See Article page XXX.

\section{Commentary: Isolated tricuspid valve surgery: It's not for everyone}

\author{
Linda J. Schulte, MD, and Harold G. Roberts, Jr, MD
}

Faerber and colleagues ${ }^{1}$ show that in patients undergoing isolated tricuspid valve (ITV) surgery for tricuspid regurgitation (TR), the model for end-stage liver disease (MELD) score is a useful risk-stratification tool beyond the commonly used Society of Thoracic Surgeons (STS) Predicted Risk of Mortality and European System for Cardiac Operative Risk Evaluation II. The difference was particularly striking in patients with MELD $\geq 20$, in which mortality was triple that predicted by either existing risk model. Although not technically demanding, ITV surgery comprises only $10 \%$ of tricuspid valve procedures, partly due to the high-risk patient population. ${ }^{2}$ Operative mortality in recent series ranges from $3 \%$, at a single-institution cohort, to $10 \%$ in a multicenter registry. ${ }^{3,4}$ The $7 \%$ mortality in the current series, which certainly represents a hand-selected single-center cohort, highlights the need for further improvement in patient selection for ITV surgery.

The authors are commended for showing that MELD score as an ordinal variable is highly predictive of 30-day mortality. In fact, using only the 4 variables available in MELD (ie, creatinine, international normalized ratio, bilirubin, and sodium), the authors calculate a C-statistic (a measure of a model's ability to predict a given outcome) of $74 \%$, whereas the full model for mortality of the STS risk calculator for isolated valve surgery is only modestly higher at $77 \%{ }^{5}$ This demonstrates how closely renal and liver function are tied to outcomes in this patient population because the risk of mortality due to bleeding or multiorgan failure rises significantly as MELD rises. These data show

\footnotetext{
From the Division of Cardiothoracic Surgery, Department of Surgery, Washington University School of Medicine, Barnes-Jewish Hospital, St Louis, Mo.

Disclosures: The authors reported no conflicts of interest.

The Journal policy requires editors and reviewers to disclose conflicts of interest and to decline handling or reviewing manuscripts for which they may have a conflict of interest. The editors and reviewers of this article have no conflicts of interest.

Received for publication Dec 14, 2021; revisions received Dec 14, 2021; accepted for publication Dec 15, 2021

Address for reprints: Harold G. Roberts, Jr, MD, Division of Cardiothoracic Surgery, Department of Surgery, Washington University School of Medicine, Barnes-Jewish Hospital, 660 S Euclid Ave, St Louis, MO 63110 (E-mail: h.g.robertsjr@wustl. edu).

J Thorac Cardiovasc Surg 2021; $\mathbf{\square}: 1-2$

$0022-5223 / \$ 36.00$

Copyright (C) 2021 by The American Association for Thoracic Surgery

https://doi.org/10.1016/j.jtcvs.2021.12.020
}

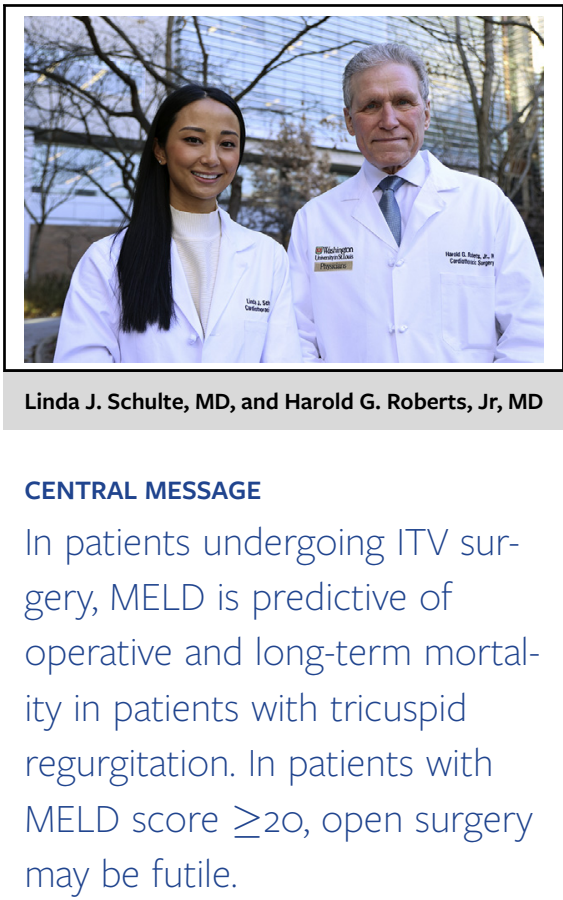

that with a 30-day mortality of $31 \%$ and a median survival of 6 months, ${ }^{1}$ ITV surgery in patients with MELD score $\geq 20$ may be futile, and these patients may be better served by medical management or, possibly, transcatheter options. Although the retrospective nature of this analysis did not include time of diagnosis of TR to time of surgery, higher MELD score may be indicative of delayed referral or a longer disease progression leading to irreversible hepatic and renal injury. Moving forward, MELD score should be included as not only a tool of risk-stratification at the time of surgery, but also a temporal marker of TR management that guides earlier treatment.

It is tempting to view ITV surgery as low-hanging fruit when it comes to minimally invasive approaches. Nearly all patients in the present series were treated using minimally invasive access on a beating heart, whereas nearly one-third of patients also underwent concomitant procedures such as closure of patent foramen ovale or atrial septal defect. Notably, the rate of stroke was high at $4 \%$, and especially high $(8 \%)$ in patients with MELD score $\geq 20$. As always, the surgeon is cautioned of the risk of air emboli due to unsuspected intracardiac shunts whenever he or she is performing beating-heart surgery.

The current study by Faerber and colleagues ${ }^{1}$ is an important addition to our armamentarium of risk-stratification tools for patients with TR needing ITV surgery. Despite 
limitations as a single-center cohort analysis, its serves as an important signal MELD score should be included in large prospective registries such as the STS Adult Cardiac Surgery Database to inform new iterations of large-scale, validated risk-prediction models.

\section{References}

1. Faerber G, Marx J, Scherag A, et al. Risk stratification for isolated tricuspid valve surgery assisted by model of end-stage liver disease score. J Thorac Cardiovasc Surg. 2022. XX;XX-X.
2. Zack CJ, Fender EA, Chandrashekar P, Reddy YNV, Bennett CE, Stulak JM, et al. National trends and outcomes in isolated tricuspid valve surgery. J Am Coll Cardiol. 2017;70:2953-60.

3. Dreyfus J, Flagiello M, Bazire B, Eggenspieler F, Viau F, Rian E, et al. Isolated tricuspid valve surgery: impact of aetiology and clinical presentation on outcomes. Eur Heart J. 2020;41:4304-17.

4. Hamandi M, Smith RL, Ryan WH, Ryan WH, Grayburn PA, Vasudevan A, et al. Outcomes of isolated tricuspid valve surgery have improved in the modern era. Ann Thorac Surg. 2019;108:11-5.

5. O'Brien SM, Feng L, He X, Xiang Y, Jacobs JP, Badhwar V, et al. The Society of Thoracic Surgeons 2018 adult cardiac surgery risk models: part 2-statistical methods and results. Ann Thorac Surg. 2018;105:1419-28. 